\title{
Ensino de genética no ensino médio: uma análise estatística das concepções prévias de estudantes pré-universitários
}

\section{Teaching genetics in high school: a statistical analysis of previous conceptions from pre-university students}

\author{
${ }^{1}$ Michel Stórquio Belmiro michelbio@yahoo.com.br \\ ${ }^{2}$ Marcelo Diniz Monteiro de Barros
}

\section{RESUMO}

Devido a crescentes avanços da genética, cada vez mais é necessário o conhecimento para a tomada de decisões pelos cidadãos. A escola tem um papel crucial nesse processo de construção do conhecimento, embora tenha se mostrado falho em diversos aspectos. O objetivo desse estudo foi investigar as concepções prévias de estudantes do ensino médio sobre conceitos fundamentais em genética. A investigação mostrou que a maioria dos estudantes apresentava concepções errôneas do ponto de vista científico. Este fato pode estar relacionado à descontinuidade no processo de ensino-aprendizagem. Assim, um diagnóstico através da identificação das concepções dos estudantes pode ajudar o educador a alcançar melhores resultados no processo de aprendizagem, pois existe a possibilidade de melhor adaptação do assunto às dificuldades dos estudantes, principalmente no atual momento de discussão e planejamento de uma base nacional comum curricular (BNCC).

Palavras-chave: Ensino de genética, pesquisa em educação básica, concepções prévias.

\begin{abstract}
Due to increasing advances in genetics, knowledge and instruction in this area to the citizens are indispensable to help them in important decision-making. The school has a crucial role in this knowledge construction process, although it has been shown to be fail in several aspects. The aim of this study was to investigate the previous conceptions of high school students about fundamental concepts in genetics. The investigation showed that the major of the students had misconceptions from scientific point of view. This fact can be related due to the discontinuity in the teaching-learning process. Thus, a diagnostic through the identification of students' conceptions may help the educator to achieve better results in the learning process, because there is the possibility of better adapting the theme to the students' difficulties, especially at this moment of discussion and planning a curriculum common national basis ( BNCC).
\end{abstract}

Keywords: Teaching of genetics, research in basic education, misconceptions

1 Pós graduado em ensino de biologia e mestrando em Genética pela Universidade Federal de Minas Gerais

2 Professor Adjunto IV do Departamento de Ciências Biológicas da Pontifícia Universidade Católica de Minas Gerais 


\section{INTRODUÇÃO}

As crescentes informações decorrentes das recentes descobertas científicas, principalmente nas áreas da Genética, Biologia Molecular e Biotecnologia, tem se disseminado amplamente do meio acadêmico para o público em geral, através de revistas de divulgação científica e dos meios de comunicação de massa (Silva \& Freitas, 2006; Valério \& Bazzo, 2006). No momento histórico atual são recorrentes os assuntos polêmicos de cunho científico como clonagem, uso de células-tronco embrionárias e, principalmente, a utilização de organismos transgênicos (Leite, 2000; Pedrancini et al., 2007; Pedrancini et al., 2008). Para a compreensão dessa nova gama de informações, é necessário à população um conhecimento básico de genética, desde a estrutura do DNA até os mecanismos de transmissão das características hereditárias. A escola, portanto, torna-se fundamental nesse processo, pois o cidadão depende de diversas informações para compreender os conteúdos e tomar decisões (Auler \& Delizoicov, 2001; Justina \& Leyder Da Rosa, 2000).

É comum os professores de Biologia relatarem grande dificuldade no ensino de genética, pois necessita-se, por parte do estudante, de um elevado grau de abstração para o entendimento dos conteúdos (Salim et al., 2007) e as aulas práticas são, geralmente, inviáveis devido ao planejamento indevido das atividades prático-experimentais (Gomes et al., 2008), alto número de estudantes e à falta de tempo e de materiais necessários, em geral de elevado custo (Possobom et al., 2003), apesar de haver alternativas de baixo custo como proposto por Martinez \& Paiva (2008). A organização curricular sugerida também tem grande contribuição nessa dificuldade: ácidos nucleicos e divisão celular são usualmente abordados no primeiro ano do ensino médio, enquanto que a genética é discutida apenas no terceiro ano do ensino médio. Isso retrata uma evidente descontinuidade no ensino (Amorim, 2001), visto que a estrutura cromossômica e os mecanismos de transmissão das informações genéticas nela armazenadas dependem, em última análise, da própria estrutura molecular dos ácidos nucleicos e da duplicação do DNA (Justina, 2001).

Essa dificuldade fica evidente quando se observam que falta nos estudantes uma compreensão global dos processos de divisão celular, estrutura, localização e função do material genético, além da sua relação com a transmissão de caracteres hereditários (Banet \& Ayuso, 1995; Scheid \& Ferrari, 2006; Wood-Robinson et al., 1998). Diante dessa realidade é possível dizer que o ensino de genética mostra-se pouco eficaz da maneira como é organizado e conduzido (Pedrancini et al., 2007; Pedrancini et al., 2008).

Pesquisas em Ensino de Ciências e Biologia demonstram a importância do conhecimento das concepções prévias dos estudantes no processo de ensino-aprendizagem (Mortimer, 1996). Conceitos errôneos do ponto de vista científico (misconceptions) podem representar um obstáculo no processo de aprendizagem (Schnetzler, 1992), mas também podem ser transformados em concepções cientificamente aceitas (Posner et al., 1982; Schnetzler, 1992).

Para que tal transformação seja efetiva é necessário que o educador instaure uma situação de conflito ao estudante, o qual, insatisfeito com suas idéias prévias, necessite buscar outras concepções para a explicação do problema, o que leva a um progressivo processo de mudança conceitual das concepções prévias pelas concepções apresentadas pelo docente (Mortimer, 1996). Para tal, é necessário ao professor o conhecimento das concepções prévias dos estudantes para o desenvolvimento dessas situações-problemas (Schnetzler, 1992).

Todas essas questões, apresentadas na revisão de literatura, motivaram a realização do presente estudo, cujo objetivo foi fazer uma análise investigativa sobre as concepções prévias de estudantes do ensino médio da rede de ensino pública (municipal, estadual e federal) e privada a respeito dos conceitos e fenômenos biológicos fundamentais ao ensino de genética. 
O trabalho foi realizado com estudantes de um curso pré-vestibular no município de Contagem, MG, durante o primeiro semestre de 2010. Os estudantes são provenientes de escolas públicas e privadas da região, constituindo um grupo extremamente heterogêneo.

A pesquisa foi do tipo descritiva, quantitativa e de campo, sendo o questionário o instrumento de coleta de dados utilizado (Barros \& Lehfeld, 2007). O referido questionário (Anexo A) apresentava 20 questões que buscavam dados referentes à escola de origem, idade, sexo, curso superior pretendido, período do dia que frequentavam as aulas do pré-vestibular, bem como perguntas sobre conceitos e fenômenos biológicos fundamentais e, frequentemente, apontados como problemáticos no ensino de genética (cromossomo, gene, alelo, divisões celulares, redundância do código genético, probabilidade e ploidia). Perguntou-se também se os estudantes gostavam e possuíam dificuldades em genética. Foram coletados dados de sete salas (extensivos e intensivos) nos três turnos (manhã, tarde e noite). A coleta dos dados foi realizada por amostragem, totalizando uma média de 30 estudantes por sala.

O percentual de acertos nas questões e itens foi confrontado com os dados de idade e escola de origem através do teste One-way Anova. Utilizou-se, ainda, o Student-Newman-Keuls Method para comparações. Os dados não paramétricos foram analisados pelo teste Kruskal-Wallis One-way (Randles \& Wolfe, 1979). Para avaliar a influência do sexo, gosto e dificuldade pela disciplina com o percentual de acertos utilizou-se o teste T Student (Lehmann \& Romano, 1986; Mayers, 2013). Os testes foram realizados através do Programa Sigma Plot 11 (Systat Software, Inc.).

\section{RESULTADOS E DISCUSSÃO}

Foram amostrados 208 estudantes (117 do sexo feminino e 91 do sexo masculino), dentre os quais 29 (13,9\%) ainda não haviam concluído o Ensino Médio (Tab.1). Dos estudantes amostrados, a maioria é proveniente de escola estadual (85), seguido por 57 de escola privada, 53 de municipal e 13 de federal (Tab.1, Fig.1). A média de idade do período da manhã foi de 19 anos, enquanto no período da tarde foi de 17 anos e 20 anos no período da noite (Tab.1).

Tabela 1: Caracterização dos estudantes de acordo com o período em que frequentam o curso prévestibular.

\begin{tabular}{|c|c|c|c|c|c|c|c|c|c|}
\hline \multirow{2}{*}{$\begin{array}{c}\text { Período } \\
\text { do dia }\end{array}$} & \multirow{2}{*}{$\begin{array}{c}\text { Média de idade } \\
\text { (anos) }\end{array}$} & \multirow{2}{*}{$\begin{array}{l}\text { Não concluíram o } \\
\text { ensino médio }(\%)\end{array}$} & \multicolumn{4}{|c|}{ Escola de origem } & \multicolumn{2}{|c|}{ Percentual de estudantes que possuem } & \multirow{2}{*}{$\begin{array}{l}\text { Percentual } \\
\text { de acertos }\end{array}$} \\
\hline & & & Estadual & Federal & Municipal & Privada & Gosto por genética & Dificuldade em genética & \\
\hline Manhã & 19 & 2,2 & 36,0 & 3,4 & 23,6 & 37,1 & 83,1 & 55,1 & 55,7 \\
\hline Tarde & 17 & 62,1 & 34,5 & 6,9 & 37,9 & 20,7 & 72,4 & 58,6 & 48,2 \\
\hline Noite & 20 & 10,0 & 47,8 & 8,9 & 23,3 & 20,0 & 84,4 & 73,3 & 48,2 \\
\hline Total & 19,5 & 13,9 & 42,0 & 6,0 & 25,0 & 27,0 & 40,6 & 35,3 & 50,7 \\
\hline
\end{tabular}

FONTE: Dados da pesquisa

O curso superior mais pretendido pelos estudantes de escolas estaduais foi engenharia civil (15\%) seguido por medicina (11\%). Em relação aos estudantes de escolas federais, as maiores opções verificadas foram engenharia civil (23\%) e mecânica (23\%). Os estudantes de escolas municipais assinalaram as suas preferências por medicina (15\%) e por direito (13\%), da mesma forma que os estudantes de escolas privadas (35\% medicina e $12 \%$ direito).

A média de acertos do período da manhã foi 55,7\% e nos períodos da tarde e noite foram 48,2\% em ambos (Tab.1). O sexo não se mostrou uma variável significativa no percentual de acertos dos estudantes ( $\mathrm{p}=0.589)$. 
Não existe diferença estatisticamente significativa entre a média de acertos obtida pelos extensivos e intensivos $(\mathrm{p}=0.861)$. Houve diferença entre as médias de acertos no que diz respeito ao período em que o estudante frequenta o curso ( $\mathrm{p}=<0.001)$. A diferença significativa foi entre o período da manhã e o da noite. Houve diferença significativa entre as médias dos estudantes que terminaram o ensino médio $(\approx 52 \%)$ e os que não o fizeram $(\approx 44 \%)(\mathrm{p}=0,02)$. Existe diferença estatisticamente significativa entre a média de acertos dos estudantes que consideraram genética difícil $(\approx 49 \%)$ dos que não consideraram $(\approx 55 \%)(\mathrm{p}=0,020)$. Os itens com os maiores números de acertos foram: 20 - C ( $\approx 85 \%)$ e 20 - D ( $\approx 82 \%)$, enquanto os itens 20 - A ( $\approx 15 \%)$ e 20 - B ( $\approx 11 \%)$ tiveram os menores índices de acertos (Tab.2).

Tabela 2: Percentual de acertos (\%) nas questões e itens do questionário aplicado aos estudantes de prévestibular de acordo com o assunto abordado e escolas de origens.

\begin{tabular}{|c|c|c|c|c|c|c|}
\hline \multirow{2}{*}{ Questōes } & \multirow{2}{*}{ Assunto Abordado } & \multicolumn{4}{|c|}{ Percentual de acertos (\%) de estudantes por escolas } & \multirow{2}{*}{ Percentual total de acertos $(\%)$} \\
\hline & & Estaduais & Federais & Municipais & Privadas & \\
\hline 10 & Células Somáticas & 32,9 & 69,2 & 43,4 & 42,1 & 40,4 \\
\hline 11 & Condensação do DNA & 21,2 & 61,5 & 13,2 & 29,8 & 24,0 \\
\hline 12 & Alelo & 50,6 & 46,2 & 41,5 & 50,9 & 48,1 \\
\hline 13 & Gene & 76,5 & 76,9 & 67,9 & 70,2 & 72,6 \\
\hline 14 & Redundância do código genético & 25,9 & 46,2 & 26,4 & 28,1 & 27,9 \\
\hline 15 & Herança & 72,9 & 69,2 & 75,5 & 82,5 & 76,0 \\
\hline 16 & Cromossomos sexuais & 35,3 & 61,5 & 43,4 & 50,9 & 43,3 \\
\hline 17 & Divisōes Celulares & 61,2 & 76,9 & 69,8 & 66,7 & 65,9 \\
\hline 18 & Probabilidade & 36,5 & 76,9 & 49,1 & 59,6 & 48,6 \\
\hline $19-\mathrm{A}$ & Clonagem (Genética x Ambiente) & 74,1 & 92,3 & 75,5 & 86,0 & 78,8 \\
\hline $19-\mathrm{B}$ & Clonagem (Genética x Ambiente) & 50,6 & 69,2 & 50,9 & 59,6 & 54,3 \\
\hline $20-\mathrm{A}$ & Cromossomos (Ploidia) & 10,6 & 30,8 & 7,5 & 24,6 & 14,9 \\
\hline $20-B$ & Cromossomos (Ploidia) & 10,6 & 23,1 & 5,7 & 12,3 & 10,6 \\
\hline $20-C$ & Cromossomos (Ploidia) & 82,4 & 84,6 & 79,2 & 93,0 & 84,6 \\
\hline $20-\mathrm{D}$ & Cromossomos (Ploidia) & 78,8 & 69,2 & 81,1 & 89,5 & 81,7 \\
\hline \multicolumn{2}{|c|}{ Média total (\%) } & 48,0 & 63,6 & 48,7 & 56,4 & 51,4 \\
\hline
\end{tabular}

Identificamos em nossa pesquisa que todos os estudantes possuíam conhecimentos sobre os assuntos abordados. Entretanto, ainda apresentavam concepções errôneas do ponto de vista científico (misconceptions), principalmente no que se refere às diferentes condensações do DNA (76\% de erro na questão 11) e a estrutura organizacional dos cromossomos e ploidia celular ( $\approx 89 \%$ de erro no item B da questão 20$)$. Aproximadamente 57\% dos estudantes declararam não haver cromossomos sexuais em células da pele (Questão 16), bem como que as células somáticas do indivíduo podem ter seqüências genéticas diferentes (Questão 10). Isso pode estar relacionado à crença de que as células só possuem os genes ou cromossomas que necessitam, corroborando os dados de Lewis (2000) e Lewis \& Kattman (2004). Esses autores demonstraram que muitos dos estudantes não possuem o conhecimento que os genes podem estar ativos ou inativos nas diferentes células do corpo e que todas as células de um organismo contêm a mesma informação genética. Banet \& Ayuso (1995) verificaram que muitos estudantes acreditavam que apenas os gametas possuíam cromossomos sexuais. Outra questão que obteve um baixo índice de acertos foi referente à redundância do código genético (questão 14). Apenas $\approx 28 \%$ dos estudantes mostraram conhecer a característica redundante do código genético, a qual uma mutação em um nucleotídeo pode não alterar, necessariamente, o aminoácido codificado (mutação silenciosa).

O percentual de acerto na questão $12(\approx 48 \%)$ evidenciou que a maioria dos estudantes não associa o termo alelo ao gene, mostrando, talvez, um desconhecimento sobre os cromossomos homólogos e as possibilidades de alelia gênica. Os genes são, comumente, representados na forma de letras maiúsculas (dominantes) e minúsculas (recessivos), como demonstrado por Boujemaa et al. (2010), mas sem maiores esclarecimentos de outras possibilidades de alelos e possibilidades fenotípicas. O uso de propostas alternativas no ensino de conteúdos relacio- 
nados com diversidade alélica e fenotípica podem representar uma forma eficiente de transformação conceitual, como Bastos et al. (2010) e Campos Junior et al. (2009) propõem no caso do ensino dos grupos sanguíneos ABO.

Outro ponto crucial no ensino de genética é a probabilidade, geralmente associada à matemática. Na questão 18, cerca de metade dos estudantes erraram a probabilidade real de um acontecimento no cruzamento. Dentre esses estavam erros de multiplicação de frações, mas - principalmente- equívocos interpretativos. Isso mostra um ponto de dificuldade por parte dos estudantes em associar conhecimentos de cruzamentos com cálculos matemáticos. Propositalmente, não foi utilizada a preposição "e” para abordar a exigência do produto do cruzamento ser uma menina "e" albina. Pretendíamos avaliar a capacidade do estudante em entender o problema e resolver de forma consciente e não apenas com o uso da famosa "regra do $e$ " e do "ou", uma vez que o ensino da genética tem sido desenvolvido, principalmente, pela resolução de cruzamentos, muitas vezes solucionados de forma mecânica, como nos assevera Silveira (2008).

Com relação à clonagem e expressão do genótipo no ambiente (fenótipo) a maioria dos estudantes mostrou conhecimentos satisfatórios quanto à influência do meio e ao não determinismo genético, como se pode analisar a partir do índice de acerto no item A da questão 19 ( $\approx 79 \%)$, porém apenas cerca de $54 \%$ justificaram de forma adequada o item B da mesma questão. Realizando o mesmo questionamento, Paiva \& Martins (2005) encontraram resultados semelhantes (83 \% de acerto) com estudantes do terceiro ano do Ensino Médio de uma escola técnica federal.

Em relação ao baixo índice de acerto nos itens A e B, contrastando com um maior percentual dos itens C e D da questão $\mathrm{n}^{\circ}$ 20, pode-se notar o equívoco de cerca de $89 \%$ dos estudantes amostrados, os quais associam ploidia com a quantidade de cromátides dos cromossomos.

Existe uma diferença estatisticamente significativa entre os tipos de escola $(\mathrm{p}<0,001)$. Os estudantes das escolas federais obtiveram as melhores médias (Tab.2), embora não houvesse diferença estatística entre as escolas Federal vs. Privada, assim como entre as escolas Municipais vs. Estaduais ( $>0,05)$. Estudantes de instituições estaduais, municipais e privadas obtiveram baixos índices de acertos nas questões referentes aos assuntos “células somáticas” (Questão 10), “condensação do DNA” (Questão 11), “cromossomos sexuais em células somáticas” (Questão 16) e "probabilidade em cruzamentos” (Questão 18) (Tab.2). Entretanto, os assuntos "alelos gênicos” (questão 12), "redundância do código genético" e "ploidia” (questão 20) obtiveram menores índices de acertos por estudantes de todas as origens (Tab.2), fato relevante, uma vez que são conhecimentos básicos para um bom entendimento da genética (Brasil, 2000; Justina, 2001).

O presente estudo forneceu informações referentes às dificuldades e concepções equivocadas ou alternativas de estudantes provenientes de diferentes instituições de ensino privadas e públicas, mas também pode servir como uma base e inspiração para o exercício da pesquisa em ensino pelos profissionais em educação, uma vez que, munido de tais informações, o educador pode obter melhores resultados no tocante a uma mudança conceitual efetiva e, portanto, sucesso no processo de ensino-aprendizagem.

\section{CONSIDERAÇÕES FINAIS}

No contexto específico desse estudo verificou-se que muitos estudantes ainda apresentam dificuldades no entendimento de vários temas a respeito de genética, possivelmente devido à descontinuidade no processo de ensino-aprendizagem. Portanto, a identificação das concepções prévias dos estudantes pode servir de base para o planejamento de situações-problemas, a fim de possibilitar aos estudantes a construção de concepções cientificamente aceitas a partir do conflito com suas ideias prévias. Espera-se, ainda, que o trabalho contribua, mesmo que de forma bastante modesta, para o aprimoramento do ensino de genética no país, principalmente no atual momento de discussão e planejamento de uma base nacional comum curricular (BNCC) . 


\section{AGRADECIMENTOS}

Aos professores Irisval Neto, José Gabriel e Paulo Marcos Lopes pela oportunidade de realização deste trabalho. À profa. Dra. Yumi Oki e ao prof. Dr. Henrique Paprocki pelo auxílio nas análises estatísticas. Agradecemos, também, a todos os estudantes que se dispuseram a participar da pesquisa.

\section{REFERÊNCIAS BIBLIOGRÁFICAS}

Amorim, A. C. R. (2001). O que foge do olhar das reformas curriculares: nas aulas de biologia, o professor como escritor das relações entre ciência, tecnologia e sociedade. Ciência e Educação, 7(1), 47-65.

Auler, D. \& Delizoicov, D. (2001). Alfabetização Científico-Tecnológica para quê? Ensaio - Pesquisa em Educação em Ciências, 3(1), 105-115.

Banet, E. \& Ayuso, G.E. (1995). Introducción a la genética en la enseñanza secundaria y bachillerato: I. Contenidos de enseñanza y conocimientos de los alumnos. Enseñanza de las Ciencias, 13(2), 137-153.

Barros, A. J. S. \& Lehfeld, N. A. S. (2007). Fundamentos de Metodologia Científica. São Paulo: Pearson Prentice Hall.

Bastos, R. W.; Martinelli, F. S. \& Tavares, M. G. (2010). Brincando com o sistema sanguíneo: proposta alternativa para o ensino dos grupos sanguíneos ABO. Genética na Escola, 5(2), 38-41.

Boujemaa, A.; Pierre, C.; Sabah, S.; Salaheddine, K.; Jamal, C. \& Abdellatif, C. (2010). University students' conceptions about the concept of gene: Interest of historical approach. US-China Education Review, 7, 9-15.

Brasil (2000). Parâmetros Curriculares Nacionais (Ensino Médio): Ciências da Natureza, Matemática e suas Tecnologias. Secretaria de Educação Média e Tecnológica- Brasília: MEC/SEMTEC, 110p.

Campos Junior, E. O.; Pereira, B. B.; Luiz, D. P.; Moreira-Neto, J. F.; Bonetti, A. M. \& Kerr, W. E. (2009). Sistema sanguíneo sem mistério: uma proposta alternativa. Genética na Escola, 4(1), 7-9.

Gomes, A. D. T.; Borges, A. T. \& Justi, R. (2008). Processos e conhecimentos envolvidos na realização de atividades práticas: Revisão da literatura e implicações para a pesquisa. Investigações em Ensino de Ciências, 13(2), 187-207.

Justina, L. A. D. \& Leyser Da Rosa, V. (2000). Genética no ensino médio: temáticas que apresentam maior grau de dificuldade na atividade pedagógica. In: Coletânea do VII Encontro "Perspectivas do ensino de Biologia", São Paulo: FEUSP, 794-795.

Justina, L. A. D. (2001). Ensino de genética e história de conceitos relativos à hereditariedade. Dissertação de Mestrado (Programa de Pós-Graduação em Educação) UFSC, Florianópolis.

Lehmann, E. L., \& Romano, J. P. (1986). Testing statistical hypotheses (Vol. 150). G. Casella (Ed.). New York et al: Wiley.

Leite, M. (2000). Biotecnologias, clones e quimeras sob controle social: missão urgente para a divulgação científica. São Paulo em Perspectiva, 14(3), 40-44.

Lewis, J. (2000). Genes, chromossomes, cell division and inheritance -do students see any relationship? International Journal of Science Education, 22(2), 177-195. 
Lewis, J. \& Kattmann, U. (2004). Traits, genes, particles and information: re-visiting student's understanding of genetics. International Journal of Science Education, 26(2), 195-206.

Martinez, E. R. M. \& Paiva, L. R. S. (2008). Eletroforese de ácidos nucléicos: uma prática para o ensino de genética. Genética na Escola, 3(1), 43-48.

Mayers, A. (2013). Introduction to statistics and SPSS in psychology. Pearson.

Mortimer, E. F. (1996). Construtivismo, mudança conceitual e ensino de ciências: para onde vamos? Investigações em Ensino de Ciências, 1(1), 20-39.

Paiva, A. L. B. \& Martins, C. M. C. (2005). Concepções prévias de alunos de terceiro ano do Ensino Médio a respeito de temas na área de Genética. Ensaio - Pesquisa em Educação em Ciências, 7(3).

Pedrancini, V. D.; Corazza-Nunes, M. J.; Galuch, M. T. B.; Moreira, A. L. O. R. \& Ribeiro, A. C. (2007). Ensino e aprendizagem de Biologia no Ensino Médio e a apropriação do saber científico e biotecnológico. Revista Electrónica de Enseñanza de las Ciencias, 6(2), 299-309.

Pedrancini, V. D.; Corazza-Nunes, M. J.; Galuch, M. T. B.; Moreira, A. L. O. R.\& Nunes, W. M. C. (2008). Saber científico e conhecimento espontâneo: opiniões de estudantes do ensino médio sobre transgênicos. Ciência \& Educação, 14, 135-146.

Posner, G. J.; Strike, K. A.; Hewson, P. W. \& Gertzog, W. A. (1982). Accommodation of a Scientific Conception: Toward a Theory of Conceptual Change. Science Education, 66(2), 211-227.

Possobom, C. C. F.; Okada, F. K. \& Diniz, R. E. S. (2003). Atividades práticas de laboratório no ensino de biologia e de ciências: relato de uma experiência. Cadernos dos Núcleos de Ensino, 1, 113-123.

Randles, R. H., \& Wolfe, D. A. (1979). Introduction to the theory of nonparametric statistics (Vol. 1). New York: Wiley.

Salim, D. C.; Akimoto, A. K.; Ribeiro, G. B. L.; Pedrosa, M. A. F.; Klautau-Gumarãe, M. N. \& Oliveira, S. F. (2007). O baralho como ferramenta no ensino de genética. Genética na Escola, 2(1), 6-9.

Scheid, N. M. J. \& Ferrari, N. (2006). A história da ciência como aliada no ensino de genética. Genética na Escola, 1(1), 17-18.

Schnetzler R. P. (1992). Construção do Conhecimento e Ensino de Ciências. Em aberto, 55, 17-22.

Silva, G. B. \& Freitas, D. S. (2006). Quando a genética vira notícia: o uso de textos de divulgação científica (TDC) em aulas de biologia. Revista Didática Sistêmica, 3, 41-56.

Silveira, L. F. S. (2008). Uma contribuição para o ensino de Genética. Dissertação de Mestrado (Programa de Pós-Graduação em Educação em Ciências e Matemática) Pontifícia Universidade Católica do Rio Grande do Sul, Porto Alegre.

Valério, M. \& Bazzo, W. A. (2006). O papel da divulgação cientifica em nossa sociedade de risco: em prol de uma nova ordem de relações entre ciência, tecnologia e sociedade. Revista de Ensino de Engenharia, 25(1), 3139.

Wood-Robinson, C.; Lewis, J.; Leach, J. \& Driver, R. (1998). Genética y formación científica: resultados de un proyecto de investigación y sus implicaciones sobre los programas escolares y la enseñanza. Enseñanza de las Ciencias, 16(1), 43-61. 


\section{ANEXO A: \\ QUESTIONÁRIO DE PESQUISA APLICADO AOS ESTUDANTES DE PRÉ-VESTIBU- LAR.}

\section{Questionário de Pesquisa}

1) Idade:

2) Sexo: $\square$ Feminino $\square$ Masculino

3) Sala: $\quad \square$ Intensivo $\square$ Extensivo

4) Período: $\square$ Manhã $\quad \square$ Tarde $\square$ Noite

5) Já concluiu o Ensino Médio? $\square \operatorname{Sim} \square$ Não

6) Onde concluiu (concluirá):

$\square$ Escola privada $\square$ Escola estadual $\square$ Escola municipal $\square$ Escola federal

7) Para qual curso superior prestará o vestibular/Enem?

8) Gosta da matéria genética? $\square$ Sim $\square$ Não

9) Tem dificuldades em genética? $\square$ Sim $\square$ Não

10) "Com exceção dos gametas, todas as células de um indivíduo possuem a mesma seqüência genética" Esta afirmação está correta? $\square$ Sim $\square$ Não

11) Existe diferença entre DNA, Cromatina e Cromossomo? $\square$ Sim $\square$ Não Em caso afirmativo, qual seria a principal diferença?

12) "Todo alelo é um gene"

Esta afirmação está correta? $\square$ Sim $\square$ Não

13) "Gene é a sequiência de DNA com a informação suficiente para produzir uma proteína" Esta afirmação está correta? $\square$ Sim $\square$ Não

14) "Toda alteração (mutação) no gene levará a uma alteração na proteína sintetizada a partir dele" Esta afirmação está correta? $\square$ Sim $\square$ Não

15) Todas doenças genéticas são causadas pelo genótipo recessivo (aa)? $\square$ Sim $\square$ Não

16) Existem cromossomos sexuais nas células da pele? $\square$ Sim $\square$ Não

17) "Na mitose, as células filhas terão a metade dos cromossomos"

Esta afirmação está correta? $\square$ Sim $\square$ Não

18) Em um casal existe $25 \%(1 / 4)$ de chance de nascer uma criança com albinismo, considerando que a probabilidade de nascer homem ou mulher é de $50 \%(1 / 2)$ para cada. Qual a probabilidade de nascer uma criança albina do sexo feminino?

19) A) Um clone de Albert Einstein será um novo Albert Einstein, ou um clone de Hitler será um novo Hitler? $\square$ Sim $\square$ Não

B) Por quê?

20) Indique a ploidia (n ou $2 \mathrm{n}$ ) das seguintes células:

A)

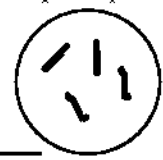

B)

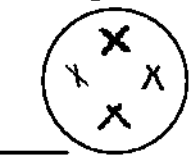

C)

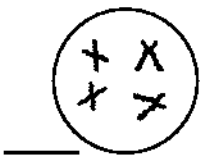

D)

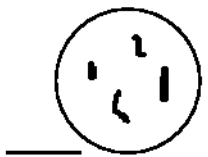

